\title{
Laser microprobe for the study of noble gases and nitrogen in single grains: A case study of individual chondrules from the Dhajala meteorite
}

\author{
R R MAHAJAN and S V S MURTY* \\ Planetary and Geosciences Division, Physical Research Laboratory, Ahmedabad 380 009, India \\ *e-mail: murty@prl.ernet.in
}

\begin{abstract}
A laser microprobe capable of analysing nitrogen and noble gases in individual grains with masses less than a milligram is described. It can be used in both continuous wave (CW) mode, useful for stepwise heating of an individual grain, as well as in pulsed mode, useful for ablating material from a small selected area of a sample, for gas extraction. We could achieve low blanks (in ccSTP units) for ${ }^{4} \mathrm{He}\left(4.8 \times 10^{-12}\right),{ }^{22} \mathrm{Ne}\left(1.0 \times 10^{-12}\right),{ }^{36} \mathrm{Ar}\left(1.0 \times 10^{-13}\right),{ }^{84} \mathrm{Kr}\left(2.9 \times 10^{-14}\right),{ }^{132} \mathrm{Xe}\left(2.6 \times 10^{-14}\right)$, and $\mathrm{N}$ $(87 \mathrm{pg})$, using this system. Preliminary data for individual chondrules from the Dhajala meteorite show that noble gases and nitrogen from grains as small as 170 microgram can be analysed using the present laser microprobe setup. The amount of trapped neon in Dhajala chondrules is very small, and nitrogen in the chondrules is isotopically heavier as compared to the bulk meteorite.
\end{abstract}

\section{Introduction}

Study of noble gases in meteorites has revealed the presence of a number of noble gas components of both local (solar system) as well as presolar origin (Reynolds 1960; Marti 1969; Lewis et al 1975; Göbel et al 1978; Anders and Zinner 1993). Similarly, nitrogen isotopic studies, often together with noble gases, pioneered by Frick and Pepin (1981), have revealed the heterogeneous distribution of nitrogen in the early solar system. To gain further insight into the true nature of the various noble gas and nitrogen components and their possible carrier phases it has become necessary to measure nitrogen and noble gases simultaneously in individual grains or phases of meteorites rather than in bulk samples. This has necessitated the development of techniques that allow measurement of noble gases and nitrogen in small samples $(\leq 1 \mathrm{mg}$ and down to a few tens of $\mu \mathrm{g})$. The gas amounts in such small samples are often very close to or even less than the typical blank levels achievable by conventional gas extraction techniques in which the sample is heated passively e.g., by resistance heating or RF heating. This problem can be overcome by using laser microprobe in which the sample is heated directly by a focussed laser beam, thereby reducing the system blank considerably.

Megrue (1967) has pioneered the laser extraction technique for applications to meteoritic studies. Using a pulsed Ruby laser he demonstrated the feasibility of the technique by analysing helium and neon content and isotopic composition in two meteorites. York et al (1981) have used the laser microprobe for determining the ${ }^{40} \mathrm{Ar} /{ }^{39} \mathrm{Ar}$ ages of terrestrial minerals. Individual mineral grains from primitive meteorites have also been studied for their neon isotopic records by laser microprobe (Hohenberg et al 1990) to infer activity of the early Sun. Norris et al (1981) have first attempted to use a laser microprobe to measure nitrogen content in lunar samples. Later, Franchi et al (1986) have refined the laser microprobe method for nitrogen, carbon and oxygen isotopic studies. They used a pulsed laser and encountered two major problems. First, the coating of the ejected material from

Keywords. Laser; mass spectrometer; noble gases; nitrogen; chondrule; meteorite. 


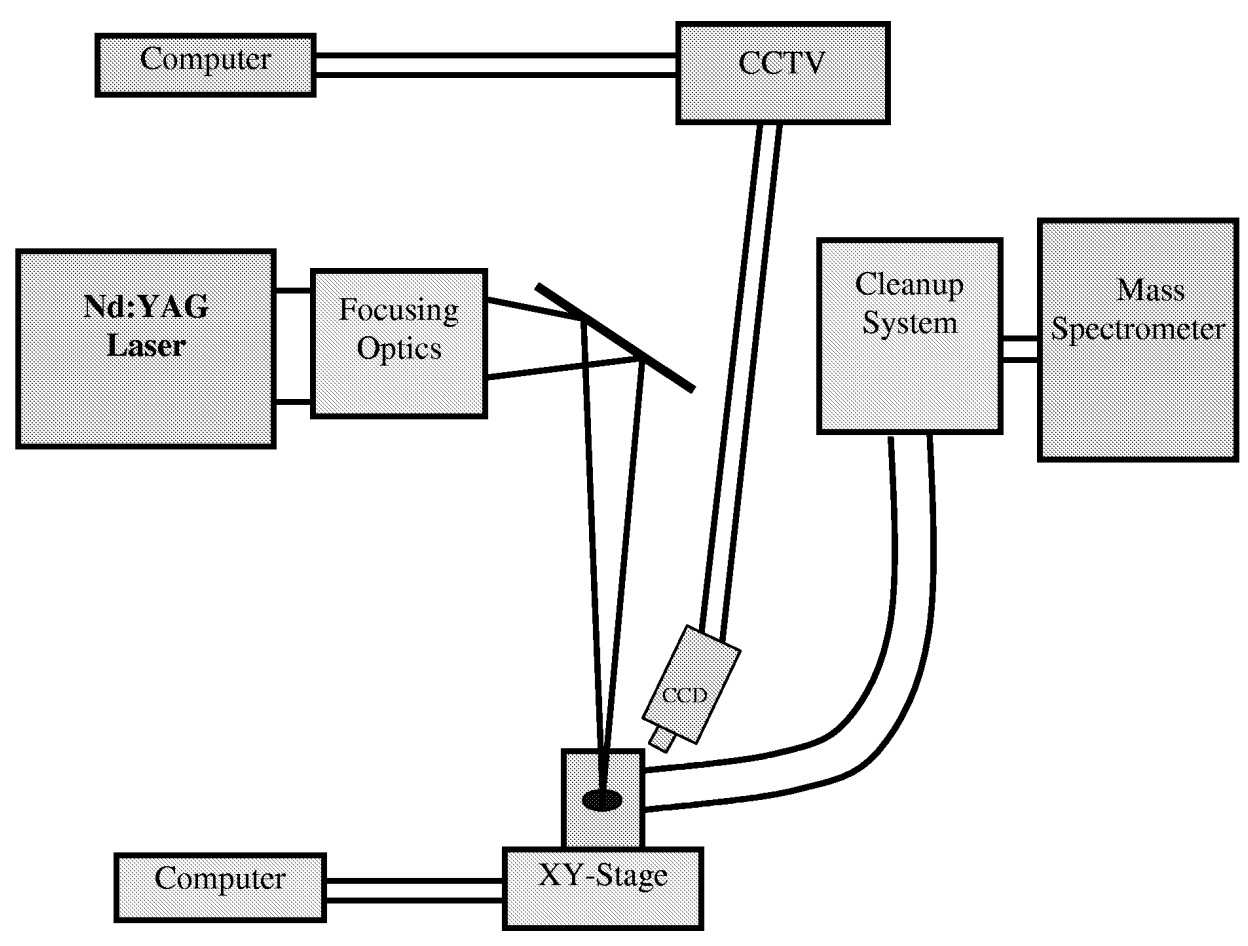

Figure 1. Schematic of the laser microprobe setup.

the sample onto the optical window of the sample holder (following laser irradiation of the sample), resulted in attenuation of laser energy reaching the sample surface during successive irradiation steps. Second, the measured $\delta^{15} \mathrm{~N}$ values (the deviation of ${ }^{15} \mathrm{~N} /{ }^{14} \mathrm{~N}$ ratio in the sample from that of standard, expressed in parts per thousand) of multiple samples of the Murchison meteorite showed a large variation from +12.4 to $+60.6 \%$ with apparent $\mathrm{N}$ concentrations that range from 82 to $417 \mathrm{ppm}$. The $\delta^{15} \mathrm{~N}$ values are found to be closer to the true bulk Murchison value whenever the contents of nitrogen gas extracted were the highest. For those extractions where smaller concentrations of nitrogen were observed, a wider range of $\delta^{15} \mathrm{~N}$ values were obtained $(+12.4,+15.6,+60.3 \%$ ). They could not ascertain if the isotopically distinct nitrogen originates from various phases that could be present within the analysed region or from the outer margins of this region. By using continuous wave laser radiation one can eliminate such ambiguities. Further, single grain analysis will also eliminate the interference from the surrounding material, present during analysis of composite phases. Single lunar mineral grains have been studied recently to understand the variations seen in the nitrogen isotopic composition in lunar samples (Wieler et al 1999) as well as the relative abundances of noble gases in the ancient solar wind (Wieler et al 1996). A laser microprobe has been recently set up at the Physical Research Laboratory, Ahmedabad, for the simultaneous analysis of nitrogen and noble gases in micro- scopic samples as well as in individual grains. We have also designed and fabricated an all-metal ultra high vacuum (UHV) cleanup system to get low system blanks. Here we report in detail the laser microprobe system and results of an initial study of sub-mg size individual chondrules from the Dhajala meteorite.

\section{Experimental setup}

The setup of the laser microprobe is shown schematically in figure 1 . It consists of

- laser,

- sample chamber,

- XY stage,

- CCD camera,

- cleanup and separation system, and

- mass spectrometer.

\subsection{The laser system}

The laser used in this study is a Nd:YAG laser (Model SL900GT, Spectron Laser Systems, U. K.). This laser can be operated in continuous wave as well as pulsed (Q-switched) mode. At the fundamental wavelength $(1064 \mathrm{~nm})$ the maximum output of the laser in CW mode is $16 \mathrm{~W}$ and the divergence of the output beam is $1.8 \mathrm{mrad}$. In the pulsed mode the average power is $8 \mathrm{~W}$. The laser can also be operated at second harmonic, and has 
an average output power of $3 \mathrm{~W}$ at $532 \mathrm{~nm}$, operated at the pulsed mode. The pulsewidth of the Q-switched laser output is $120 \mathrm{~ns}$. The operation of laser in the CW mode is useful in uniformly heating a grain; while in the pulsed mode operation it can be used to selectively melt a part of the sample.

As different mineral grains have different absorption properties for light radiation, with some absorbing light in the visible range while others in the infra red (IR) range, we are using a laser having outputs both in IR (fundamental, $1064 \mathrm{~nm}$ ) and visible $(532 \mathrm{~nm})$ (second harmonic generation) region. For those mineral grains, which do not absorb light in either range, the laser may be operated in the Q-switch mode to dump large power in a single shot to heat/melt such mineral grains.

A HeNe laser is integrated on the main laser assembly such that its output followed the same path as that of the Nd:YAG laser beam (see figure 2). The HeNe laser serves two purposes: aiming of the main laser beam at the sample and alignment of the optical components of the focussing optics. The output of the HeNe laser is directed through two mirrors (M6, M7) in such a way that it will travel the same path as followed by both the fundamental and second harmonic outputs of the main laser. Because the lasing output of the main laser at both $1064 \mathrm{~nm}$ [invisible] and $532 \mathrm{~nm}$ [green] has high output power, they are not useful for adjusting the sample under the focusing spot, as this process can preheat the sample and gases may be lost from it. In contrast, the output power of the HeNe laser is only $2 \mathrm{~mW}$ and its wavelength [632.8 $\mathrm{nm}]$ is in the visible (red) region, making it a good tool for adjustment of the sample as well as optical alignment of the different components of the laser system, some of which have to be changed for switching the laser output from fundamental to second harmonic. A telescope is used for collimating the laser beam. Collimation is essential for getting the parallel size of output laser beam. The laser beam is then focussed by a lens to a small spot.

Characterization of the laser output power as a function of the input current or the modulation frequency (for Q-switched mode) is important before conducting any laser irradiation experiment. Figure 3 shows the output power versus Q-switch modulation frequency for wavelength $532 \mathrm{~nm}$ and a lamp current of $17.2 \mathrm{~A}$; the average power decreases as the modulation frequency increases from $3 \mathrm{kHz}$ to $10 \mathrm{kHz}$. The output power as a function of the lamp current in the CW mode of the laser for fundamental wavelength $(1064 \mathrm{~nm})$ is shown in figure 4 ; in this case the output power increases very slowly as the lamp current increases, and shows a sharp increase after a threshold current (15.5 A).
For example, in the Q-switch mode, for $3 \mathrm{kHz}$ modulation frequency at $1064 \mathrm{~nm}$, the average power is $11 \mathrm{~W}$, which implies that the peak pulse power (for $120 \mathrm{~ns}$ pulse) is $30 \mathrm{~kW}$ and the power density is $3 \times 10^{11} \mathrm{~W} / \mathrm{m}^{2}$. For continuous wave [CW] mode at $1064 \mathrm{~nm}$, and at a lamp current of $16.5 \mathrm{~A}$, the power output is $15 \mathrm{~W}$. The pumping lamp current can be varied between $11 \mathrm{~A}$ and $18 \mathrm{~A}$, so a desired power output can be set for a particular irradiation step.

\subsection{Sample chamber}

The assembly of the sample chamber is made up of stainless steel (SS). There are three parts to it (figures $5 \mathrm{a}$ and $\mathrm{b}$ ). The top flange is fitted with an optical (quartz) window that allows both 1064 and $532 \mathrm{~nm}$ radiation to pass through it with minimum attenuation. A double-sided flange forms the middle section of the chamber, which is connected to the cleanup system through a flexible stainless steel tube. The bottom SS flange is used to mount the sample holder.

An additional quartz cover slip, fitted on a nickel holder, is also mounted inside the sample chamber (figure 5b). The nickel holder is movable in a circular way using an external magnet. During the laser irradiation of any sample, the nickel holder is moved appropriately so that the quartz slip covers the region around the sample. This stops deposition of material vaporised from the sample during laser irradiation on the optical window, thus keeping its transmission of laser power intact and allowing its use over a long period. The sample holder is made of copper plate of $3 \mathrm{~mm}$ thickness. Copper is used since it is a good conductor of heat and will suppress background gases that may result from localised heating. Different sizes of blind pinholes are punched on the sample holder for loading the samples (individual grains). The sample chamber has been fixed on a platform, which is in turn fixed on the $X Y$ stage.

Online monitoring of the sample for recording the processes before, during and after the laser irradiation is necessary. This is done by using a monochrome CCD camera coupled to a zoom lens (Leica monozoom 7) for imaging and observing the sample using a CCTV and a PC that serves the purpose for online monitoring as well as image grabbing.

An $X Y$ stage is used to locate the sample at the focusing spot of the laser. By keeping the laser beam spot at a fixed location, the desired sample can be moved under the laser beam spot using the $X Y$-stage. The movement of the $X Y$-stage can be programmed. If there is a need to raster the surface of a sample (removal of few nanometers of the surface by irradiating with laser beam for short durations), the same may be done by moving the sample 


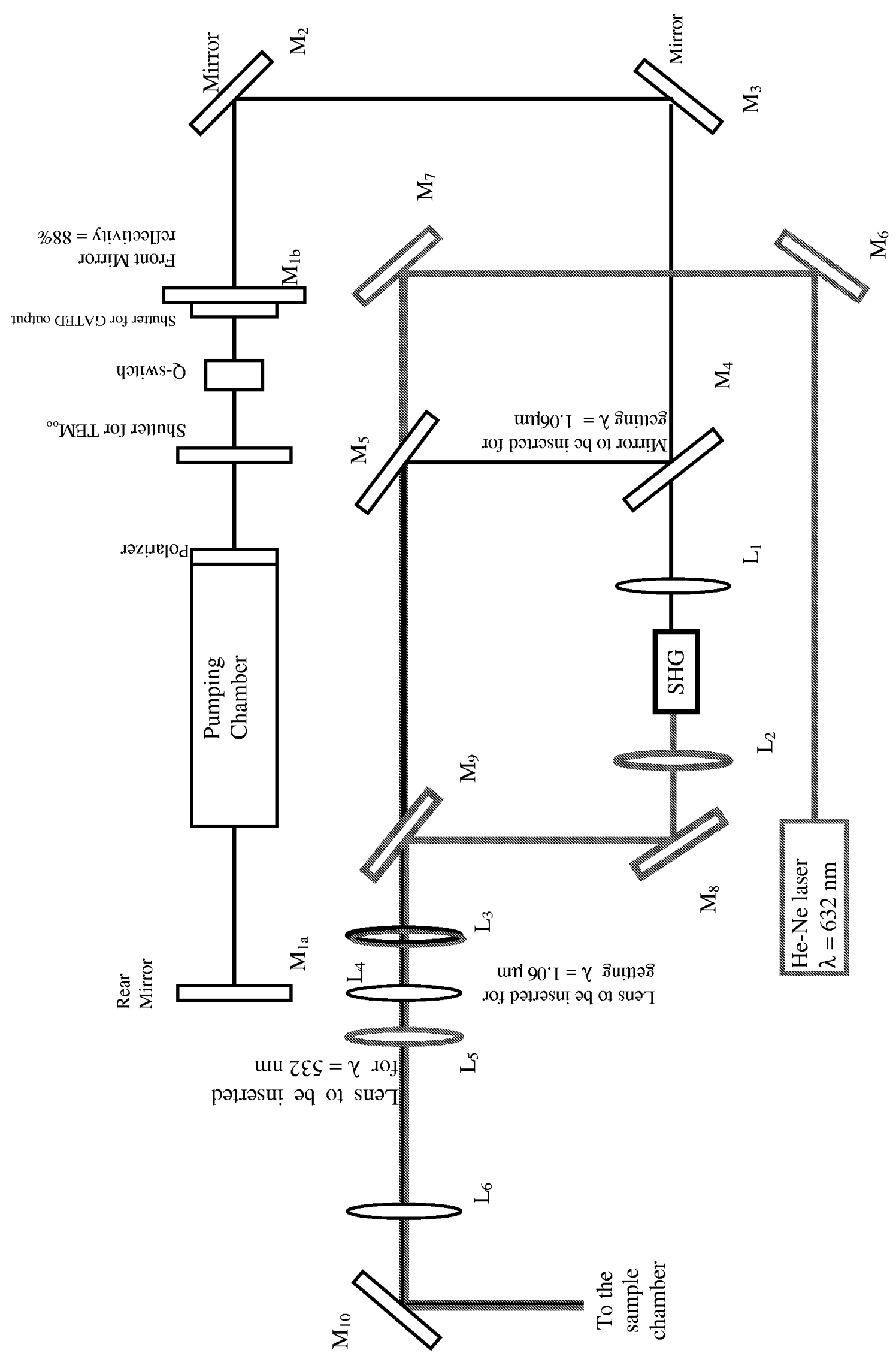




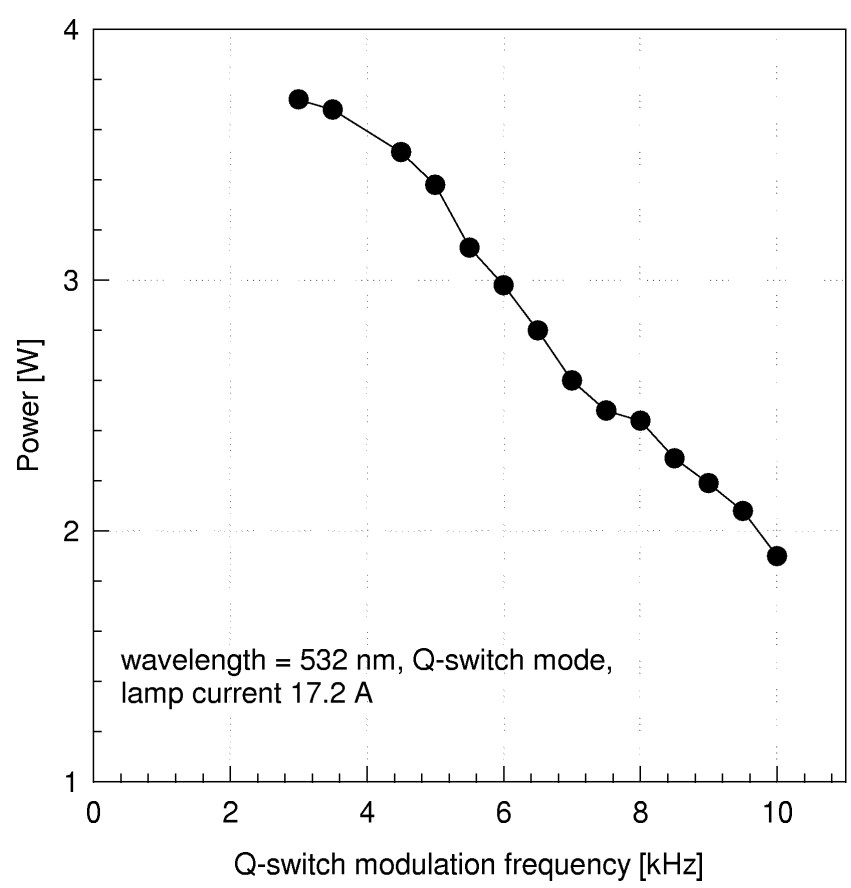

Figure 3. Power output of the laser vs Q-switch modulation frequency for the second harmonic generator $(\lambda=532 \mathrm{~nm})$ at a lamp current of $17.2 \mathrm{~A}$. This mode works like a quasi-CW mode.

across the laser beam with the desired speed. The rastering is useful for two different purposes. First, the gases coming out from surficial layers during rastering can be studied and one can have information about gases implanted to shallow depths on grain surfaces (e.g., solar wind implantation into lunar and meteoritic grains). Second, one can avoid surficial contamination by removing the top layers of the sample before studying the composition of the gases in the sample. The $X Y$-stage, fixed on a jack that allows fine vertical movement, can also be adjusted to put the sample at the exact location of the focusing spot.

\subsection{The UHV cleanup and separation system}

A new all-metal UHV cleanup system has been designed and fabricated, keeping the total volume of the system small, to achieve low system blanks.

The salient features of the extraction system are the following:

- All-metal configuration to obtain very low blanks for He and Ne. A branching line made of pyrex is added for the processing of nitrogen, as the allmetal system did not yield low and reproducible blanks for nitrogen. The whole system can be covered and baked to $300^{\circ} \mathrm{C}$ to achieve UHV and very low blanks.

- Use of a turbomolecular pump backed by a diaphragm pump to obtain hydrocarbon free UHV of $10^{-9}$ torr and use of ion pump to maintain the UHV conditions during sample analysis.

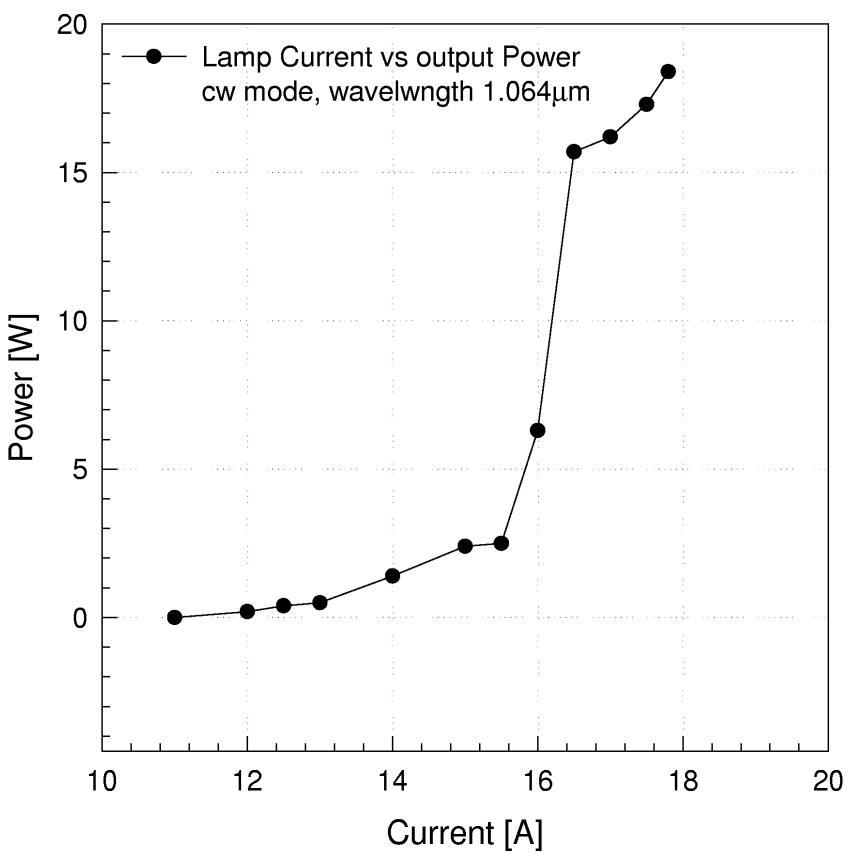

Figure 4. Power output of the laser vs lamp current for the fundamental wavelength, $\lambda=1064 \mathrm{~nm}$.

- Use of stainless steel mesh (SSM) for adsorption of noble gases and nitrogen. SSM's can be degassed up to $700^{\circ} \mathrm{C}$ thereby obtaining ultraclean conditions, without in any case affecting its adsorption/desorption characteristics. Earlier workers have used molecular sieves for $\mathrm{N}_{2}$ adsorption, which often suffered from memory effects that posed serious limitations when handling small amounts (picomoles) of $\mathrm{N}_{2}$.

The schematic of the cleanup system is shown in figure 6 . The different components of the cleanup system are: two SSM fingers, two charcoal fingers, two $\mathrm{CuO}$ fingers, two cold fingers, one Ti-sponge getter finger, and one TiZr getter finger.

The SSM is used for collecting noble gases (argon, krypton, xenon) and nitrogen by cooling it to liquid nitrogen temperature (LNT). The adsorbed gases on SSM can be desorbed, by heating the finger up to $150^{\circ} \mathrm{C}$. The second SSM finger (near the mass spectrometer) is used to collect the sample gas, which is to be introduced into the mass spectrometer. The cold finger is used to trap the unwanted and condensable gases $\left(\mathrm{H}_{2} \mathrm{O}, \mathrm{CO}_{2}\right.$ etc.) at LNT. The charcoal is used for collecting the noble gases as well as for their separation (into Ar, $\mathrm{Kr}$, and $\mathrm{Xe}$ ). The separation is achieved by keeping a temperature controller probe on the finger. There are two charcoal fingers used in the cleanup system; in the first, xenon is separated from Ar-Kr, and the later are collected on the second charcoal finger. The Ar-Kr mixture is then further separated. A TiZr getter is used to remove all the chemically reactive gases. $\mathrm{A} \mathrm{CuO}$ is used to generate 


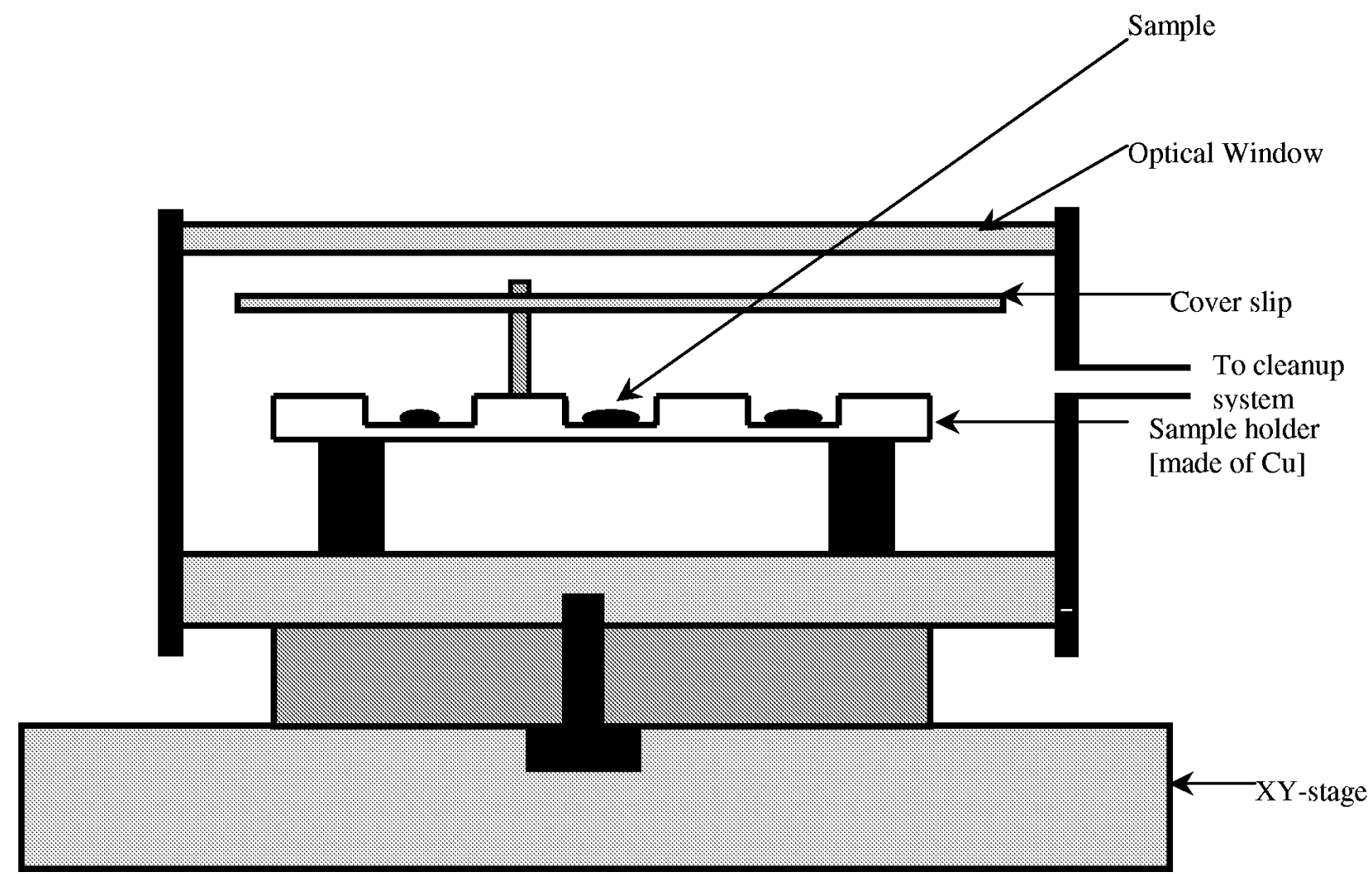

Figure 5(a). Schematic of the sample chamber. The quartz cover slip is mounted on a nickel frame to enable its positioning, through rotation, using an external magnet. This facilitates covering of the sample (and its surrounding region) under laser irradiation and prevents vapour deposition on the main quartz window.

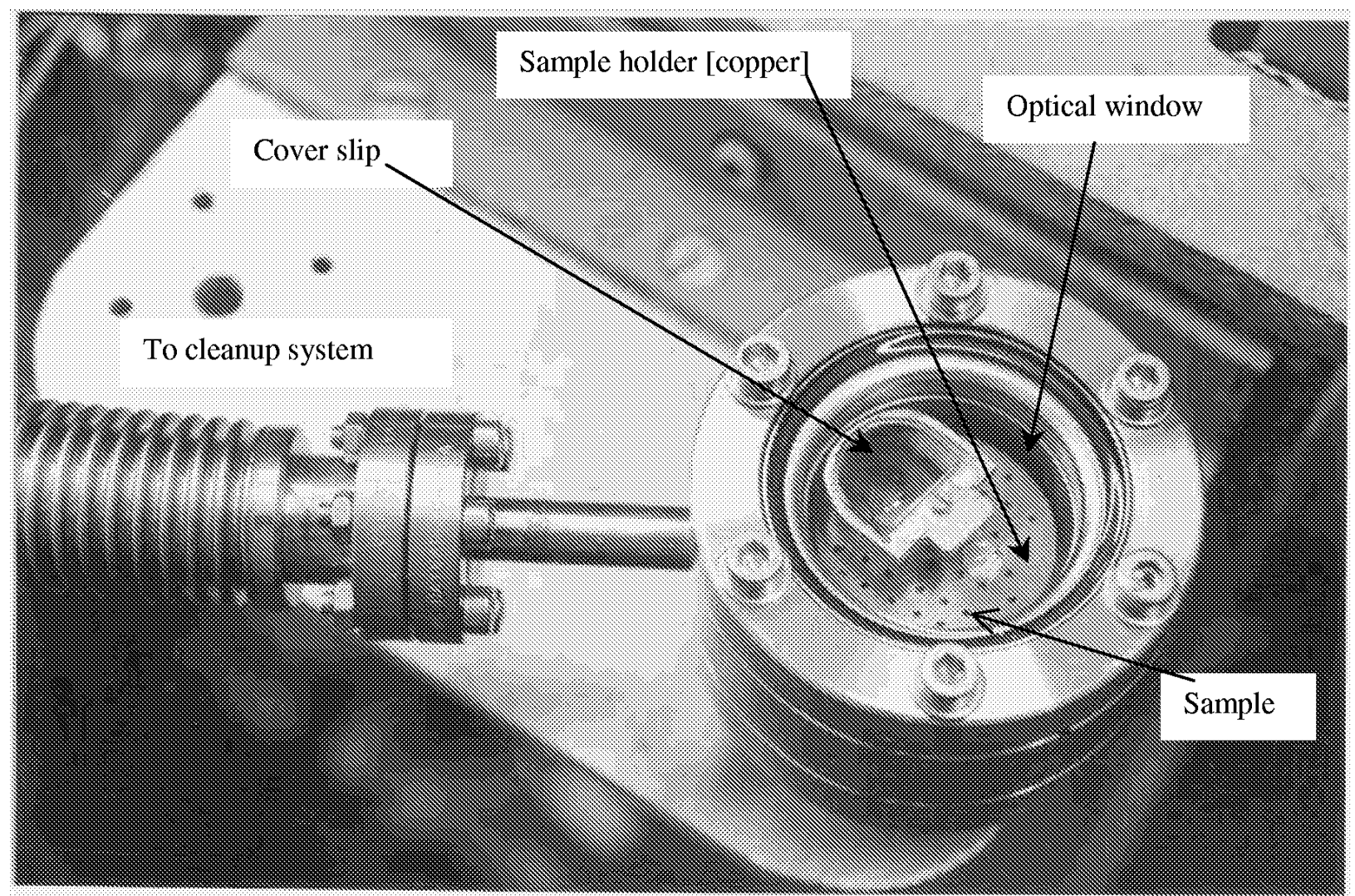

Figure 5(b). The actual sample chamber. The blind holes in the copper plate, where samples are placed and the cover glass to prevent sample vapours from reaching the quartz window can be clearly seen. 
oxygen in the cleanup system at desired pressure. Oxygen is needed to oxidize the hydrocarbons etc. into condensable gases, which can then be removed from the gas (nitrogen fraction) by using the cold trap. The condensible gases can further be removed using either the TiZr- or Ti-sponge-getter. Three pressure gauges are connected to the cleanup system to monitor the vacuum level, as well as to measure the pressure generated by the extracted gases from the sample and the pressure of oxygen generated from the $\mathrm{CuO}$.

During the initial phases of assessing the performance of the all-metal extraction system we have realized that the system does not give low and reproducible blanks for nitrogen, although no such problem existed for noble gases. This could be due to some metal surfaces in the UHV system serving as active sites for $\mathrm{N}_{2}$ to be chemisorbed. To avoid prolonged exposure of $\mathrm{N}_{2}$ released from the sample to metal surfaces of the extraction system we have introduced a separate branch line made of pyrex glass for nitrogen processing. The glass line has been integrated in the metal cleanup system in such a way that, after irradiation of sample by the laser, a volume split of the total extracted gas is isolated into the glass line within a minute for the nitrogen analysis, while the rest of the gas is processed for noble gases in the metal system.

\subsection{Operating modes of the laser microprobe}

The laser heating technique can be characterized by the operating modes of the laser: continuous wave $(\mathrm{CW})$ heating and $\mathrm{Q}$-switched heating. The applications of these two modes of operation are considerably different. The single grain gas extraction requires a $\mathrm{CW}$ output whereas in situ studies of small area in a large polished section of a sample require a Q-switched pulse output. These specific requirements will clearly depend on the coupling of the laser output and the heated material. Laser radiation in $\mathrm{CW}$ mode delivers constant energy to the sample throughout the heating/melting process, uniformly heating the target area. This is useful in the analysis where individual grains are used. However, for in situ study of individual phases in a multiphase sample, the $\mathrm{CW}$ mode of operation will lead to heating of phases surrounding the target phase that often result in unwanted degassing of the sample. Therefore, Qswitched laser output, that delivers energy to the sample in a series of short-duration pulses of highpower bursts leading to rapid heating followed by a brief cooling period over the course of each duty cycle is chosen for such analysis. This results in minimal heating of the material surrounding the target phase. Also the Q-switched laser output can be used in those samples that are transparent at $1064 \mathrm{~nm}$ or $532 \mathrm{~nm}$ wavelength and a large amount of power is required to either heat or melt the sample.

\subsection{Procedural protocols for gas extraction}

The experimental analysis of a sample using laser microprobe consists essentially the following steps: - gas extraction by laser;

- partitioning the extracted gas into N-fraction and noble gas fraction and

- cleaning, separation and measurement of each of the gas components.

Before starting the analysis of the sample, all the volumes are pumped off and all the valves are closed. The sample is irradiated by laser using $0.2 \mathrm{~W}$ to $4.5 \mathrm{~W}$ power with increasing time from $3 \mathrm{sec}$ to $1 \mathrm{~min}$. The images of the sample were monitored and stored using CCD camera, before, during and after laser irradiation.

Following the laser irradiation, a split of the released gases is taken for $\mathrm{He}$ and $\mathrm{Ne}$ analysis, after which the gas is opened to the "pyrex-line" branch to avoid buildup of $\mathrm{He}$ and $\mathrm{Ne}$ blank due to diffusion through glass. This is achieved by expanding the extracted gas and valving off a fraction for $\mathrm{He}$, Ne studies between $\mathrm{V}_{\mathrm{L} 2}$ and $\mathrm{V}_{\mathrm{L} 6}$ (see figure 6). The remaining gas is then expanded into the "pyrex-line" and a gas split is isolated for nitrogen analysis. It only takes about two minutes by the time nitrogen split is isolated, minimizing the exposure of $\mathrm{N}_{2}$ to metal. The helium and neon gas fraction is then cleaned by exposing it to the heated Ti-sponge getter, while the $\mathrm{Ar} / \mathrm{Kr} / \mathrm{Xe}$ in this volume is trapped by cooling the charcoal finger $\left[\mathrm{V}_{\mathrm{L} 4}\right]$ to LNT. Ti-sponge getter removes all chemically active gases from the volume exposed to it so that the gas fraction that has to be put inside the mass spectrometer is free from hydrocarbons. The helium and neon are let in and analysed by the mass spectrometer. During the He, Ne analysis the SSM finger kept under LNT is open to the mass spectrometer volume, to minimize the amounts of ${ }^{40} \mathrm{Ar}, \mathrm{CO}_{2}$ and water so that the interferences due to ${ }^{40} \mathrm{Ar}^{++}, \mathrm{H}_{2}^{18} \mathrm{O}^{+}\left(\right.$at $\left.{ }^{20} \mathrm{Ne}\right)$ and $\mathrm{CO}_{2}^{++}$ (at ${ }^{22} \mathrm{Ne}$ ) are minimized. Nitrogen gas fraction is cleaned by exposing it to $\mathrm{CuO}$ (wrapped in $\mathrm{Pt}$ foil) at $750^{\circ} \mathrm{C}$ for 20 minutes, to oxidise any $\mathrm{CO}$ and hydrocarbons to $\mathrm{CO}_{2}$ and $\mathrm{H}_{2} \mathrm{O}$, and subsequently to $\mathrm{CuO}$ at $400^{\circ} \mathrm{C}$ to remove excess $\mathrm{O}_{2}$. $\mathrm{CO}_{2}$ and $\mathrm{H}_{2} \mathrm{O}$ are condensed on cold finger and pure $\mathrm{N}_{2}$ fraction is transferred to let-in volume for measurement. The remaining $\mathrm{Ar} / \mathrm{Kr} / \mathrm{Xe}$ amount in the volume between the valve $\mathrm{V}_{\mathrm{L} 2}$ and the sample chamber is collected on the same charcoal finger $\left(\mathrm{V}_{\mathrm{L} 4}\right)$ by cooling it to LNT. This fraction of gas is cleaned by Ti-sponge getter and then admitted 


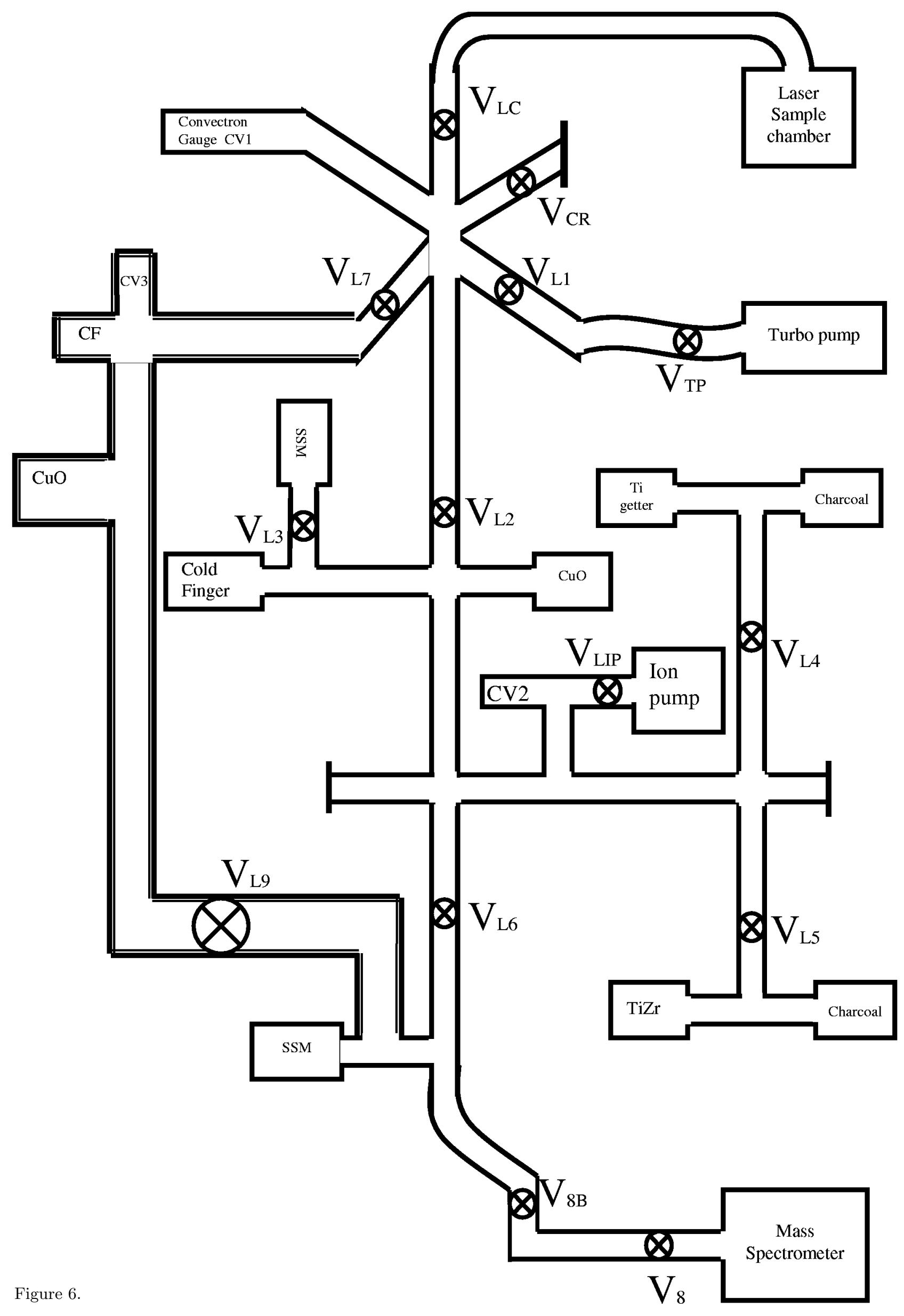


Table 1. Blank of the laser microprobe with all-metal extraction system is compared with that of conventional heating and glass extraction system.

\begin{tabular}{lcccccr}
\hline & ${ }^{4} \mathrm{He}$ & ${ }^{22} \mathrm{Ne}$ & ${ }^{36} \mathrm{Ar}$ & ${ }^{84} \mathrm{Kr}$ & ${ }^{132} \mathrm{Xe}$ & $\mathrm{N}$ \\
\hline \multicolumn{7}{c}{$10^{-12} \mathrm{ccSTP}$} \\
\hline Laser & 4.8 & 1.0 & 0.1 & 0.03 & 0.03 & 87 \\
Conventional & 150000 & 100 & 75 & 0.3 & 0.3 & 300 \\
\hline
\end{tabular}

into the mass spectrometer for analysis. The total time to complete an experiment is around four hours.

He, Ne analysis: Masses 2, 3, 4 are scanned repeatedly. Mass 2 is used to assess $\mathrm{H}_{3}^{+}$contribution at mass 3 , by using predetermined value of $\left(\mathrm{H}_{3}^{+} / \mathrm{H}_{2}^{+}\right)=4.6 \times 10^{-4}$. At the end of the analysis of Ne masses 20, 21 and 22, peaks at 40,44 and 18 are measured to estimate interferences from ${ }^{40} \mathrm{Ar}^{++}, \mathrm{CO}_{2}^{++}$and $\mathrm{H}_{2}^{18} \mathrm{O}^{+}$, using pre-determined factors $\left({ }^{40} \mathrm{Ar}^{++} /{ }^{40} \mathrm{Ar}^{+}\right)=0.11,\left(\mathrm{CO}_{2}^{++} / \mathrm{CO}_{2}^{+}\right)=$ 0.015 and $\left(\mathrm{H}_{2}^{18} \mathrm{O} / \mathrm{H}_{2}^{16} \mathrm{O}\right)=0.00204$. Interference contributions are less than $10 \%$ for most of the analysed samples. Occasionally, like in the case of chondrule S24 (see next section), whose mass is small $(0.172 \mathrm{mg})$, the signal size at mass 20 was very small and the interference correction exceeded $50 \%$, though mass 21 is clear of any interference. Hence, we do not report ${ }^{20} \mathrm{Ne} /{ }^{22} \mathrm{Ne}$ ratio for this sample.

$\mathrm{Ar} / \mathrm{Kr} / \mathrm{Xe}$ : This fraction is analysed without separating it into individual gases. First $\mathrm{Ar}$ is analysed. Usually, ${ }^{36} \mathrm{Ar}$ and ${ }^{38} \mathrm{Ar}$ amounts are very small as compared to ${ }^{40} \mathrm{Ar}$ and intensity of ${ }^{36} \mathrm{Ar}^{+}$ and ${ }^{38} \mathrm{Ar}^{+}$are measured using electron multiplier and ${ }^{40} \mathrm{Ar}^{+}$on Faraday cup, if its signal is too large for the multiplier. After completing the Ar scan, $\mathrm{Kr}$ and Xe peaks are scanned for estimating the amounts of ${ }^{84} \mathrm{Kr}$ and ${ }^{132} \mathrm{Xe}$ and the ratio ${ }^{129} \mathrm{Xe} /{ }^{132} \mathrm{Xe}$. In some cases, where the amount of $\mathrm{Xe}$ in the sample is large, the complete Xe spectrum is scanned (taking about ten scans) to obtain the isotopic composition for other Xe isotopes as well.

Nitrogen: Nitrogen is analysed in the molecular form. Signal size at masses 28 and $29\left({ }^{14} \mathrm{~N}^{14} \mathrm{~N}\right.$ and ${ }^{14} \mathrm{~N}^{15} \mathrm{~N}$ ) are usually large enough to be measured on Faraday cup. Following this, masses 29 and 30 $\left({ }^{15} \mathrm{~N}^{15} \mathrm{~N}+{ }^{12} \mathrm{C}^{18} \mathrm{O}\right)$ are measured on multiplier, to accurately obtain the ratio of $(29 / 30)$, so that contribution from $\mathrm{CO}$ can be assessed and corrected for (see, e.g., Murty 1997 for details).

\subsection{Sensitivities and system blanks}

Air standards are run in order to infer sensitivity and mass discrimination during analysis. The sensitivities $(\mathrm{ccSTP} / \mathrm{mV})$ are ${ }^{4} \mathrm{He}=1.865 \times$ $10^{-12},{ }^{22} \mathrm{Ne}=1.078 \times 10^{-12},{ }^{36} \mathrm{Ar}=1.556 \times$ $10^{-13},{ }^{84} \mathrm{Kr}=1.349 \times 10^{-13},{ }^{132} \mathrm{Xe}=9.275 \times 10^{-14}$ on multiplier $\left(10^{9} \Omega\right.$ resistor $)$, and ${ }^{28} \mathrm{~N}_{2}=6.35 \times$ $10^{-6} \mu \mathrm{g} / \mathrm{mV}$ (on Faraday cup, $10^{10} \Omega$ resistor). Typical mass discriminations (in \%/amu units) for various elements are: $\mathrm{He}(12) ; \mathrm{Ne}(2.1) ; \mathrm{Ar}(0.8)$; $\mathrm{Kr}(0.5) ; \mathrm{Xe}(0.3)$ and $\mathrm{N}_{2}(2.2)$.

Blanks were measured using the same setup with the laser beam firing at an empty spot on the copper sample holder (at maximum power used for sample analysis). The blank amounts are considerably small as compared to the conventional extraction system. The blanks of the metal cleanup system are given in table 1 and are compared with blanks from conventional heating in a glass system.

\section{Results of a study of individual chondrules from the Dhajala meteorite}

Chondrules are once molten silicate droplets that abundantly occur in chondritic meteorites (figure 7). Their chemical, mineralogical and petrological features suggest their formation by flash heating followed by rapid cooling of preexisting silicates in the solar nebula, though the source of this heat energy as well as the nebular location of chondrule formation are still not well understood (Rubin 2000). Presence of fossil records of short lived radio-nuclides in chondrules suggest that they have formed over an extended period of time (1 to $5 \mathrm{Ma}$ ) after the formation of calcium-aluminium-rich inclusions (CAIs), that are considered to be some of the first solids to form in the solar nebula (Russell et al 1996; Mostefaoui et al 1999). Oxygen isotopic studies reveal that the precursors of chondrules

\section{Figure 6 caption}

Figure 6. Schematic of the all-metal gas extraction and cleaning system. $\mathbf{V}=$ Valve; $\mathbf{C V}=$ Convectron gauge; $\mathbf{C F}=$ Cold finger; SSM = Stainless steel mesh finger; the double-lined segment is the pyrex line branch for nitrogen processing. 


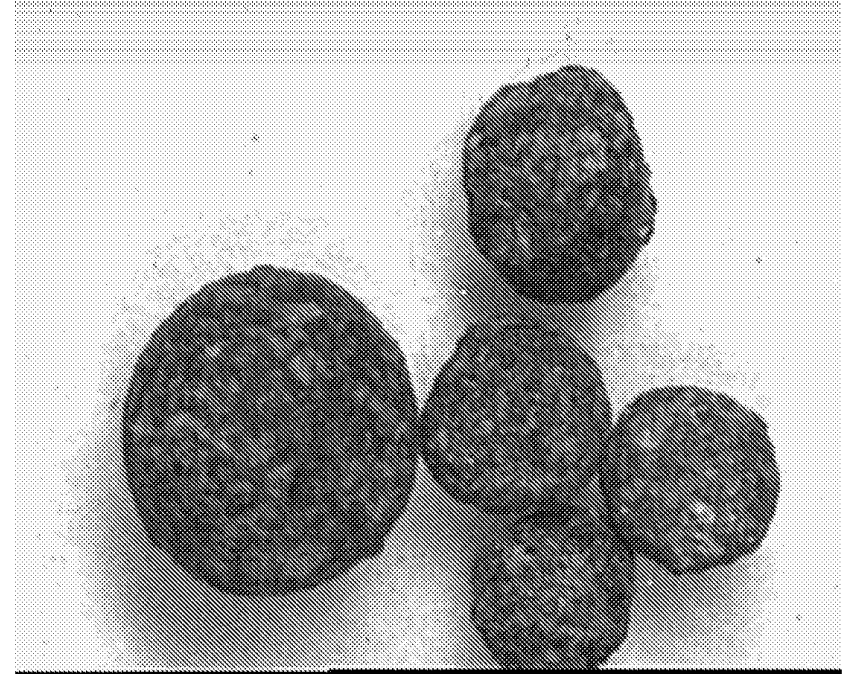

Figure 7. Chondrules of different sizes from the Dhajala meteorite.

were different from their host meteorites (Clayton et al 1991). Studies of size separated chondrules have also revealed possible oxygen isotopic exchange of ${ }^{16} \mathrm{O}$ poor chondrule precursor with a ${ }^{16} \mathrm{O}$ rich nebular gas (Clayton et al 1991). If a considerable time gap existed between the formation of chondrules in the nebula and their aggregation into chondritic parent bodies, they might have experienced a precompaction energetic particle (cosmic ray) irradiation in the solar nebula, which can lead to an excess in cosmogenic noble gas content in them with respect to the matrix material (Polnau et al 1999, 2001). Recently, trapped noble gases of sub-solar composition have been found in the chondrules of an enstatite chondrite (Okazaki et al 2001), favouring a model of chondrule formation at a location close to the Sun (Shu et al 2001). The different precursors of chondrules as well as gas (nebular) solid (precursor) exchange might show up as differences in noble gas and nitrogen isotopic composition in the chondrules. We have initiated a systematic study of noble gases and nitrogen in individual chondrules to understand the chondrule formation process and their aggregation into chondritic parent bodies. Here we report our preliminary results obtained from a study of chondrules from the Dhajala $\mathrm{H}(3.8)$ chondrite. We have analysed 12 individual Dhajala chondrules by our laser microprobe. Individual chondrules of size $\geq 300 \mu \mathrm{m}$ were picked from the fragment Dhajala-261 for this study; their masses range from 0.172 to $1.365 \mathrm{mg}$.

We have first established the optimum conditions for gas extraction (i.e., the appropriate wave length, power, duration of irradiation and number of steps) for complete gas release and the minimum sample mass that can be analysed. Initially
Table 2. Gas extraction from chondrule $S-3$ (1.365 mg), using $532 \mathrm{~nm}$ radiation and $Q$ switch mode.

\begin{tabular}{|c|c|c|c|c|c|}
\hline \multirow[b]{2}{*}{$\begin{array}{l}\text { Step } \\
\text { no }\end{array}$} & \multirow[b]{2}{*}{$\begin{array}{l}\text { Time } \\
\text { sec. }\end{array}$} & \multirow[b]{2}{*}{$\begin{array}{l}\text { Power } \\
\text { watts }\end{array}$} & ${ }^{4} \mathrm{He}$ & ${ }^{22} \mathrm{Ne}$ & ${ }^{36} \mathrm{Ar}$ \\
\hline & & & \multicolumn{3}{|c|}{$10^{-8} \mathrm{ccSTP} / \mathrm{g}$} \\
\hline 1 & 10 & 1.43 & 1367 & 0.57 & 0.33 \\
\hline 2 & 10 & 1.96 & 215.2 & 0.44 & 0.13 \\
\hline 3 & 40 & 2.39 & 61.3 & 0.72 & 0.08 \\
\hline 4 & 60 & 2.56 & 6.53 & 1.08 & 0.17 \\
\hline 5 & 60 & 2.56 & 1.06 & 0.55 & 1.36 \\
\hline 6 & 60 & 2.56 & BL & BL & 1.02 \\
\hline $7^{*}$ & 60 & 4.0 & 48.5 & 0.13 & 0.57 \\
\hline Total & & & 1700 & 3.49 & 3.67 \\
\hline
\end{tabular}

*Heating by $\lambda=1064 \mathrm{~nm}$ and $\mathrm{CW}$ mode.

$\mathrm{BL}=$ Blank Level.

we analysed chondrule S3 by irradiating with green light $(532 \mathrm{~nm})$, with progressively higher power with a defocused beam to cover the whole sample area. After 7 steps ${ }^{4} \mathrm{He},{ }^{22} \mathrm{Ne}$ amounts came down to blank level, but ${ }^{36} \mathrm{Ar}$ was still being released (table 2). Another irradiation step by IR $(1064 \mathrm{~nm})$ at a higher power yielded about $15 \%{ }^{36} \mathrm{Ar}$ and some ${ }^{4} \mathrm{He}$ and ${ }^{22} \mathrm{Ne}$ as well. This clearly shows that $532 \mathrm{~nm}$ radiation is not very efficient for heating chondrules. We therefore tried $1064 \mathrm{~nm}$ irradiation on chondrule S8 and found the following heating sequence to be appropriate for complete gas extraction. Step 1: Heating for 5 sec. at low power essentially to desorb surficial (mostly atmospheric) gases. Step 2: Heating for $10 \mathrm{sec}$. to release the sample gases completely. Step 3: A reheat for $15 \mathrm{sec}$. at a slightly higher power to ensure total gas release (table 3 ). In most cases the second (main) heating step has released almost all sample gas and the re-heat only yielded $<5 \%$ of gases of the main step and the initial step mostly gave gases of atmospheric composition. We have analysed twelve chondrules ranging in mass from $0.172 \mathrm{mg}$ to $1.365 \mathrm{mg}$ for noble gases following this procedure. Four of these chondrules (S1, S23, S27 and S28) have also been analysed for nitrogen, after recognising the high nitrogen blank problem with the all-metal system during the earlier analysis and improving it by incorporating a glass branch line for nitrogen processing as discussed earlier. A series of snapshots taken for one of the chondrules before, during and after the laser irradiation are shown in figure 8 . The data reported here have been corrected for blanks, instrumental mass discrimination and interference corrections for $\mathrm{Ne}$ and $\mathrm{N}$, and the corresponding errors propagated. In table 4 the data of $\mathrm{He}, \mathrm{Ne}$ and Ar (for the totals) of the analysed chondrules are compiled, while in table 5 nitrogen data for the four chondrules are given. 
Table 3. Gas extraction from chondrule $S-8(0.605 \mathrm{mg})$ using $C W$ mode and $\lambda=1064 \mathrm{~nm}$ radiation.

\begin{tabular}{|c|c|c|c|c|c|}
\hline \multirow{2}{*}{$\begin{array}{l}\text { Step } \\
\text { no. }\end{array}$} & \multirow{2}{*}{$\begin{array}{l}\text { Time } \\
\text { sec. }\end{array}$} & \multirow{2}{*}{$\begin{array}{c}\text { Power } \\
\text { watts }\end{array}$} & ${ }^{4} \mathrm{He}$ & ${ }^{22} \mathrm{Ne}$ & ${ }^{36} \mathrm{Ar}$ \\
\hline & & & \multicolumn{3}{|c|}{$10^{-8} \mathrm{ccSTP} / \mathrm{g}$} \\
\hline 1 & 5 & 0.24 & 624.8 & 0.30 & 0.38 \\
\hline 2 & 10 & 4.30 & 1126 & 3.78 & 0.97 \\
\hline 3 & 15 & 5.6 & 10.9 & 0.33 & BL \\
\hline Total & & & 1761 & 4.40 & 1.35 \\
\hline
\end{tabular}

The smallest sample analysed in the present sample set is a chondrule weighing $0.172 \mathrm{mg}$. The total amounts of ${ }^{4} \mathrm{He},{ }^{22} \mathrm{Ne}$ and ${ }^{36} \mathrm{Ar}$ present in this sample are (in $10^{-12}$ ccSTP units) 1221, 4.3 and 2.0 respectively, while the blanks in the same units are 4.8, 1.0 and 0.1 respectively, making it possible to see the signal from the sample very easily. Blanks by the conventional heating in a glass sys-
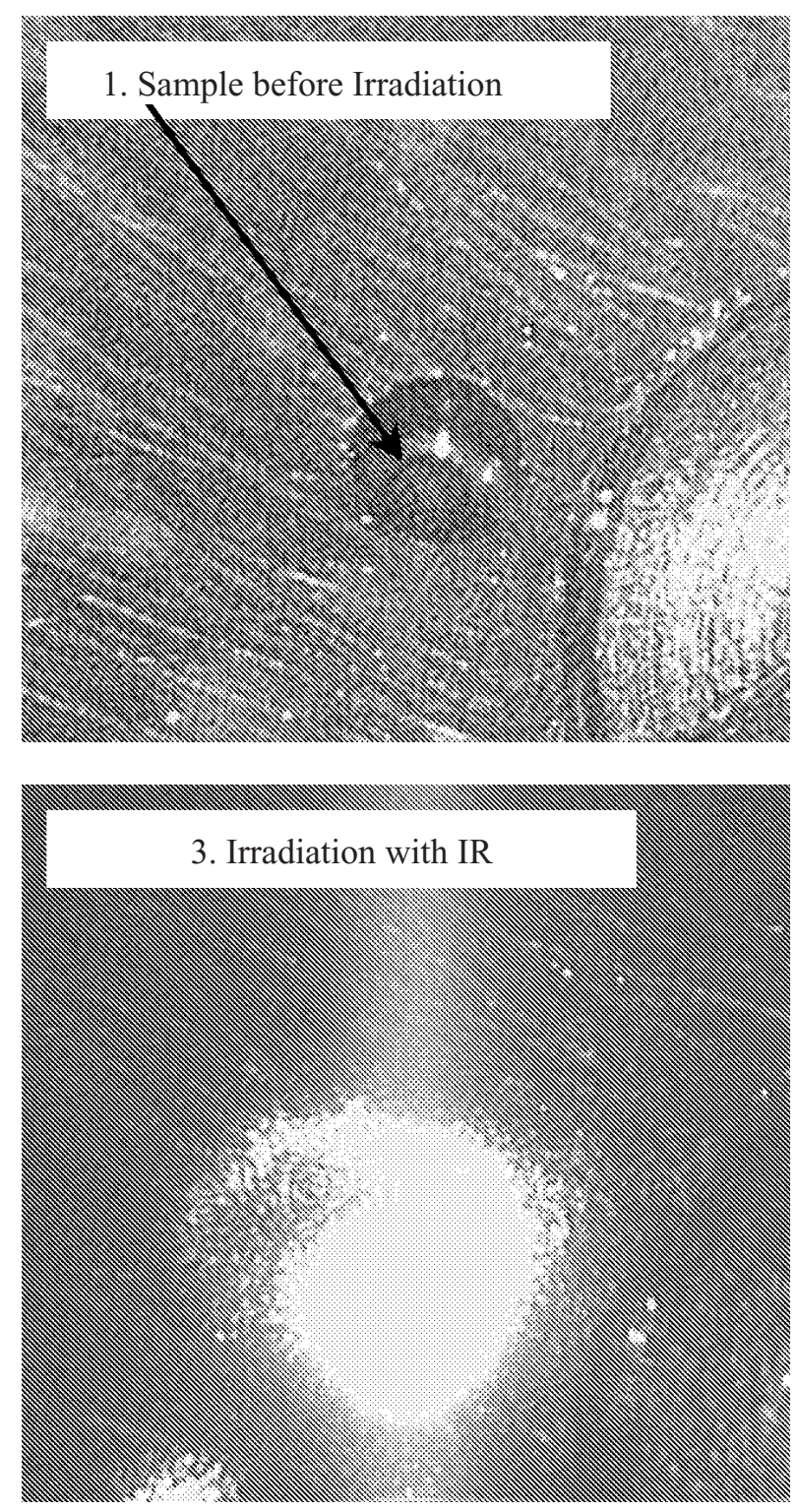

tem (see table 1) are orders of magnitude more than the sample signal and it would not have been possible to analyse this sample by extracting gases using conventional heating techniques.

\section{Discussion}

The data presented in table 4 clearly show that Ne is mostly dominated by cosmogenic component. In the Ne three isotope plot (figure 9), the data fall near the spallation end member. The presence of a small amount of trapped Ne can be explained as due to either atmospheric or most likely Ne-Q component found in the Dhajala meteorite (Schelhaas et al 1990; Murty 1996). One outlier from this trend (S1) is indicative of spallation component from a $\mathrm{Na}$ rich phase present in that chondrule.
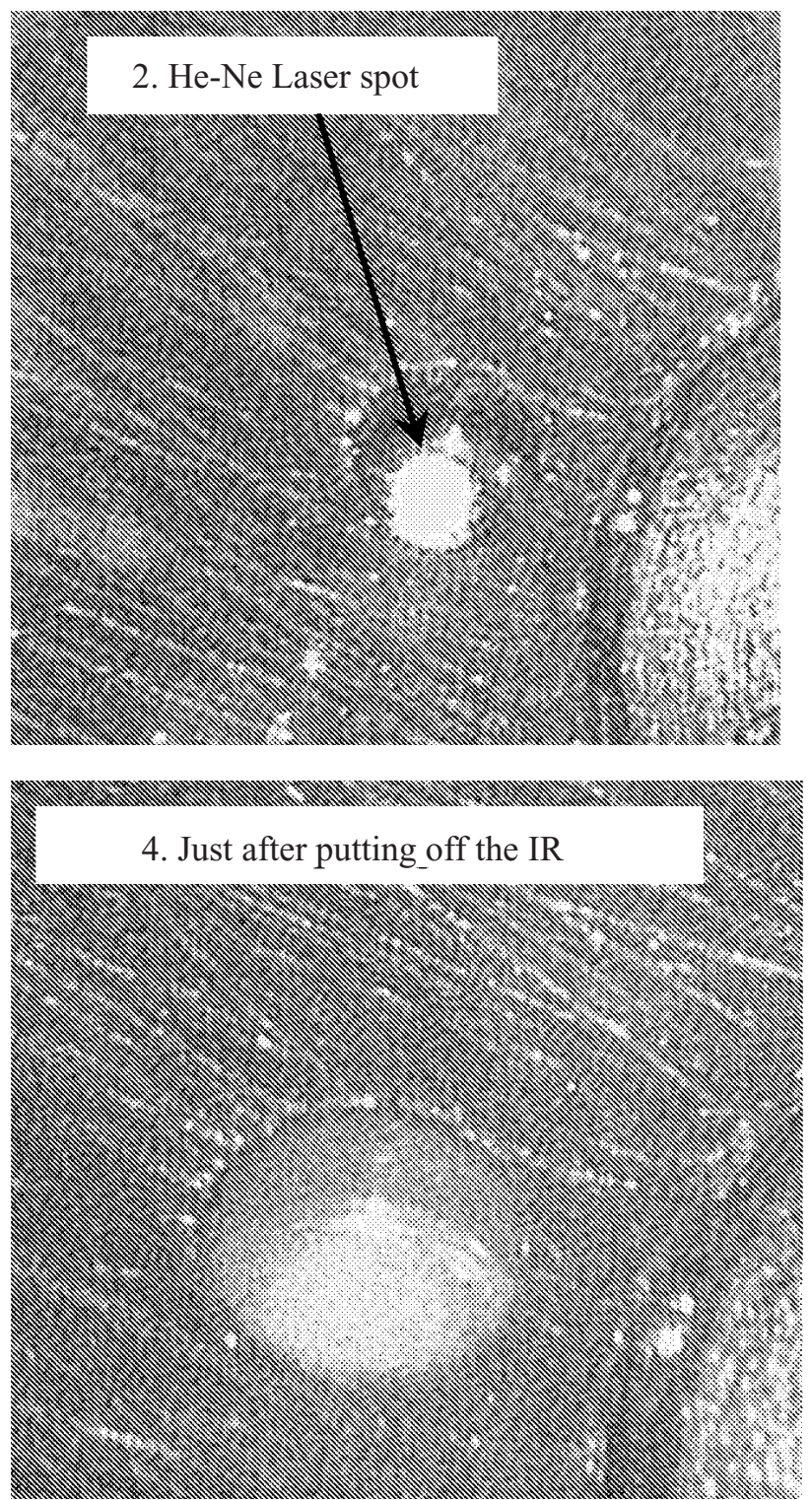

Figure 8. Various stages during the laser irradiation of a sample are shown. 
Table 4. He, Ne and Ar data for individual Dhajala chondrules (concentrations in ccSTP/g units). Errors in conc. are $\pm 10 \%$; errors in isotopic ratios represent $95 \%$ confidence limits.

\begin{tabular}{|c|c|c|c|c|c|c|c|c|c|}
\hline \multirow[b]{2}{*}{ Sample } & \multirow{2}{*}{$\begin{array}{c}\text { Mass } \\
\text { mg }\end{array}$} & ${ }^{3} \mathrm{He}$ & ${ }^{4} \mathrm{He}$ & ${ }^{22} \mathrm{Ne}$ & ${ }^{36} \mathrm{Ar}$ & \multirow{2}{*}{$\frac{{ }^{20} \mathrm{Ne}}{{ }^{22} \mathrm{Ne}}$} & \multirow{2}{*}{$\frac{{ }^{21} \mathrm{Ne}}{{ }^{22} \mathrm{Ne}}$} & \multirow{2}{*}{$\frac{{ }^{38} \mathrm{Ar}}{{ }^{66} \mathrm{Ar}}$} & \multirow{2}{*}{$\frac{{ }^{40} \mathrm{Ar}}{{ }^{36} \mathrm{Ar}}$} \\
\hline & & \multicolumn{4}{|c|}{$10^{-8}$} & & & & \\
\hline S-1 & 0.985 & 4.26 & 876 & 2.13 & 1.09 & 0.889 & 0.610 & 0.291 & 1173 \\
\hline \multirow[t]{2}{*}{$\mathrm{S}-2$} & 0.944 & 6.71 & 1769 & 2.88 & 8.13 & 1.649 & 0.880 & 0.363 & 2133 \\
\hline & & & & & & 0.022 & 0.070 & 0.010 & 17 \\
\hline \multirow[t]{2}{*}{ S-3 } & 1.365 & 6.19 & 1700 & 3.49 & 3.67 & 1.824 & 0.778 & 0.639 & 17953 \\
\hline & & & & & & 0.071 & 0.056 & 0.032 & 143 \\
\hline \multirow{2}{*}{ S-4 } & 0.993 & 7.55 & 2388 & 2.99 & 2.49 & 1.371 & 0.890 & 0.566 & 818.5 \\
\hline & & & & & & 0.012 & 0.045 & 0.016 & 6.0 \\
\hline \multirow[t]{2}{*}{ S-6 } & 0.995 & 6.84 & 2109 & 2.67 & 4.20 & 2.054 & 0.808 & 0.310 & 869.0 \\
\hline & & & & & & 0.015 & 0.059 & 0.010 & 6.8 \\
\hline \multirow[t]{2}{*}{$\mathrm{S}-8$} & 0.605 & 6.40 & 1761 & 4.40 & 1.35 & 1.574 & 0.764 & 0.349 & 9627 \\
\hline & & & & & & 0.019 & 0.038 & 0.001 & 73 \\
\hline \multirow{2}{*}{ S-9 } & 0.879 & 7.37 & 1701 & 4.04 & 14.2 & 1.616 & 0.772 & 0.379 & 536.5 \\
\hline & & & & & & 0.045 & 0.069 & 0.009 & 4.7 \\
\hline \multirow[t]{2}{*}{ S-10 } & 0.856 & 6.49 & 1247 & 2.24 & 5.00 & 1.251 & 0.998 & 0.311 & 788.3 \\
\hline & & & & & & 0.013 & 0.072 & 0.007 & 6.5 \\
\hline \multirow[t]{2}{*}{$\mathrm{S}-23$} & 0.845 & 4.16 & 829 & 2.52 & 1.69 & 1.803 & 0.701 & 0.322 & 5543 \\
\hline & & & & & & 0.043 & 0.015 & 0.002 & 40 \\
\hline \multirow[t]{2}{*}{ S-24 } & 0.172 & 2.60 & 710.2 & 2.49 & 1.18 & - & 0.638 & 0.292 & 1700 \\
\hline & & & & & & & 0.063 & 0.001 & 13 \\
\hline \multirow{2}{*}{ S-27 } & 0.805 & 3.80 & 895 & 4.89 & 1.79 & 2.550 & 0.605 & 0.320 & 522.1 \\
\hline & & & & & & 0.071 & 0.018 & 0.006 & 3.8 \\
\hline \multirow[t]{2}{*}{ S-28 } & 0.797 & 5.61 & 1712 & 3.47 & 1.73 & 2.258 & 0.634 & 0.331 & 1162 \\
\hline & & & & & & 0.045 & 0.016 & 0.003 & 8 \\
\hline
\end{tabular}

Table 5. Nitrogen in individual Dhajala chondrules.

\begin{tabular}{|c|c|c|c|c|}
\hline \multirow[b]{2}{*}{ Sample } & \multirow[b]{2}{*}{$\begin{array}{c}\mathrm{N} \\
(\mathrm{ppm})\end{array}$} & \multicolumn{2}{|c|}{$\delta^{15} \mathrm{~N}(\% \circ)$} & \multirow[b]{2}{*}{ Reference } \\
\hline & & Measured & $\begin{array}{c}\text { Cosmogenic } \\
\text { corrected }\end{array}$ & \\
\hline $\mathrm{S}-1$ & 1.30 & $106 \pm 5$ & $100 \pm 5$ & This work \\
\hline S-23 & 3.08 & $37.1 \pm 5.0$ & $33.2 \pm 5.1$ & $"$ \\
\hline S-27 & 3.89 & $47.4 \pm 1.7$ & $42.3 \pm 2.1$ & $"$ \\
\hline S-28 & 2.43 & $171 \pm 6$ & $163 \pm 6$ & $"$ \\
\hline Bulk & 4.09 & $4.84 \pm 1.44$ & $1.91 \pm 1.50$ & Murty (1996) \\
\hline Metal & 8.31 & $-11.81 \pm 1.40$ & $-11.81 \pm 1.40$ & $"$ \\
\hline Phase Q & 47.9 & $-15.06 \pm 0.63$ & $-15.06 \pm 0.63$ & $"$ \\
\hline
\end{tabular}

While He is a mixture of cosmogenic and radiogenic $\left({ }^{4} \mathrm{He}\right)$ components, Ar is a mixture of trapped and cosmogenic components $\left({ }^{36} \mathrm{Ar}\right.$ and $\left.{ }^{38} \mathrm{Ar}\right)$ and radiogenic ${ }^{40} \mathrm{Ar}$. The cosmogenic and radiogenic components calculated for each chondrule, following standard procedures (Eugster 1988) are compiled in table 6 .

The cosmogenic ${ }^{3} \mathrm{He},{ }^{21} \mathrm{Ne}$ and ${ }^{38} \mathrm{Ar}$ for the 12 chondrules vary by factors of $2.8,2.4$ and by an order of magnitude respectively while the radiogenic ${ }^{4} \mathrm{He}$ and ${ }^{40} \mathrm{Ar}$ vary by factors of 3 and 70 . While differences in chemical composition of the chondrules can lead to these variations, partial gas losses and differential cosmic ray exposure could also be possible. We can rule out differences in shielding of the chondrules within the meteorite as a plausible cause, as all chondrules come from a single, small fragment. Comparing our data with values from literature (Gopalan et al 1977; Fredriksson et al 1985), we find that the variations in ${ }^{3} \mathrm{He}$ and ${ }^{21} \mathrm{Ne}$ are similar, indicating that partial gas loss as the most probable explanation rather than a differential exposure of individual chondrules. The observed variations in ${ }^{38} \mathrm{Ar}$ and ${ }^{40} \mathrm{Ar}$ are, however, 


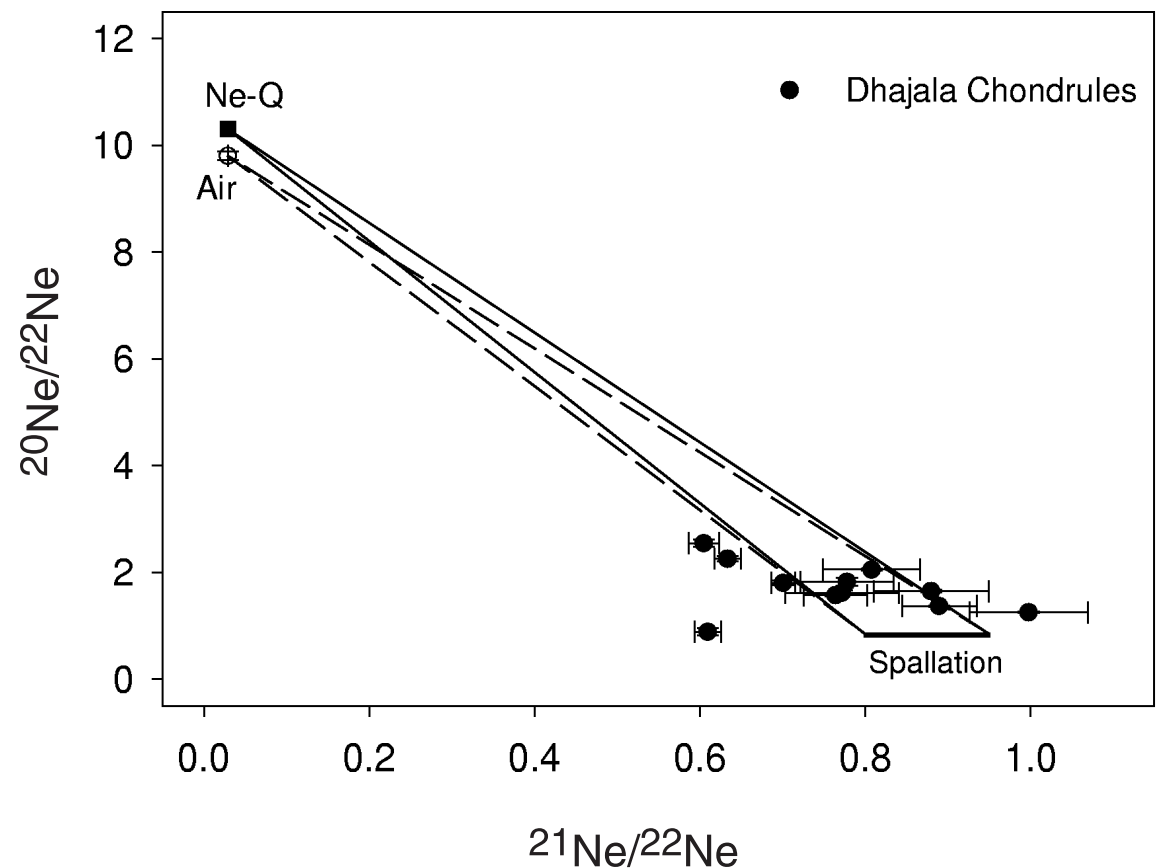

Figure 9. Ne three isotope plot for Dhajala chondrules. End member compositions for spallation, air and Ne-Q are also shown. The mixing lines between spallation and Air/Ne-Q components are shown to indicate the lack of trapped Ne.

Table 6. Cosmogenic and radiogenic noble gas components in individual Dhajala chondrules $\left(10^{-8} \mathrm{ccSTP} / \mathrm{g}\right.$ units).

\begin{tabular}{lcccccc}
\hline & \multicolumn{5}{c}{ Cosmogenic } & \multicolumn{3}{c}{ Radiogenic } & \\
\cline { 2 - 5 } Chondrule & ${ }^{3} \mathrm{He}$ & ${ }^{21} \mathrm{Ne}$ & ${ }^{38} \mathrm{Ar}$ & ${ }^{4} \mathrm{He}$ & ${ }^{40} \mathrm{Ar}$ & Reference \\
\hline S-1 & 4.26 & 1.27 & 0.13 & 853 & 1283 & This work \\
S-2 & 6.71 & 2.53 & 1.62 & 1733 & 17,336 & $"$ \\
S-3 & 6.19 & 2.70 & 1.89 & 1667 & 65,900 & $"$ \\
S-4 & 7.34 & 2.66 & 1.08 & 2286 & 2040 & $"$ \\
S-6 & 6.84 & 2.15 & 0.59 & 2073 & 3652 & $"$ \\
S-8 & 6.35 & 3.34 & 0.25 & 1761 & 12917 & $"$ \\
S-9 & 7.37 & 3.10 & 3.09 & 1663 & 7596 & $"$ \\
S-10 & 6.49 & 2.25 & 0.70 & 1213 & 3939 & $"$ \\
S-23 & 4.16 & 1.74 & 0.26 & 807 & 9380 & $"$ \\
S-24 & 2.63 & 1.56 & 0.14 & 710 & 2011 & $"$ \\
S-27 & 3.79 & 2.90 & 0.27 & 875 & 934 & $"$ \\
S-28 & 5.61 & 2.16 & 0.28 & 1683 & 2010 & $"$ \\
DH-10 & 7.90 & 3.06 & 0.31 & 1496 & 8300 & Fredriksson et al (1985) \\
DH-20 & 5.37 & 1.10 & 0.15 & 1302 & 6190 & " \\
Many & - & 2.76 & 0.30 & - & 7775 & Gopalan et al (1977) \\
Bulk (T67) & - & 2.55 & 0.34 & - & 4274 & $"$ \\
\hline
\end{tabular}

too large to be explained by partial gas loss and are most likely due to differences in $\mathrm{K}$ (for ${ }^{40} \mathrm{Ar}$ ) and $\mathrm{Ca}$ (for ${ }^{38} \mathrm{Ar}$ ) contents among the different chondrules. For example the large amount of ${ }^{40} \mathrm{Ar}$ in chondrules S3, S2 and the large amount of ${ }^{38} \mathrm{Ar}$ in $\mathrm{S} 9$ can be due to the presence of $\mathrm{K}$ rich and Ca rich phases in them. Variations in Ca contents up to a factor of 7 have been observed among the chondrules from Allegan chondrite (Fredriksson 1983), further strengthening such possible variations among the Dhajala chondrules.
Nitrogen contents among the four chondrules vary from 1.3 to $3.89 \mathrm{ppm}$ which is within the range observed for bulk Dhajala meteorite (Murty 1996). The $\delta^{15} \mathrm{~N}$ values on the otherhand are quite different from the bulk meteorite. All four chondrules have much higher $\delta^{15} \mathrm{~N}$ values as compared to the bulk meteorite. Even $\delta^{15} \mathrm{~N}$ values corrected for cosmogenic contribution by standard procedures (see Mathew and Murty 1993) are much above the bulk value, clearly suggesting the presence of a ${ }^{15} \mathrm{~N}$ enriched component in 


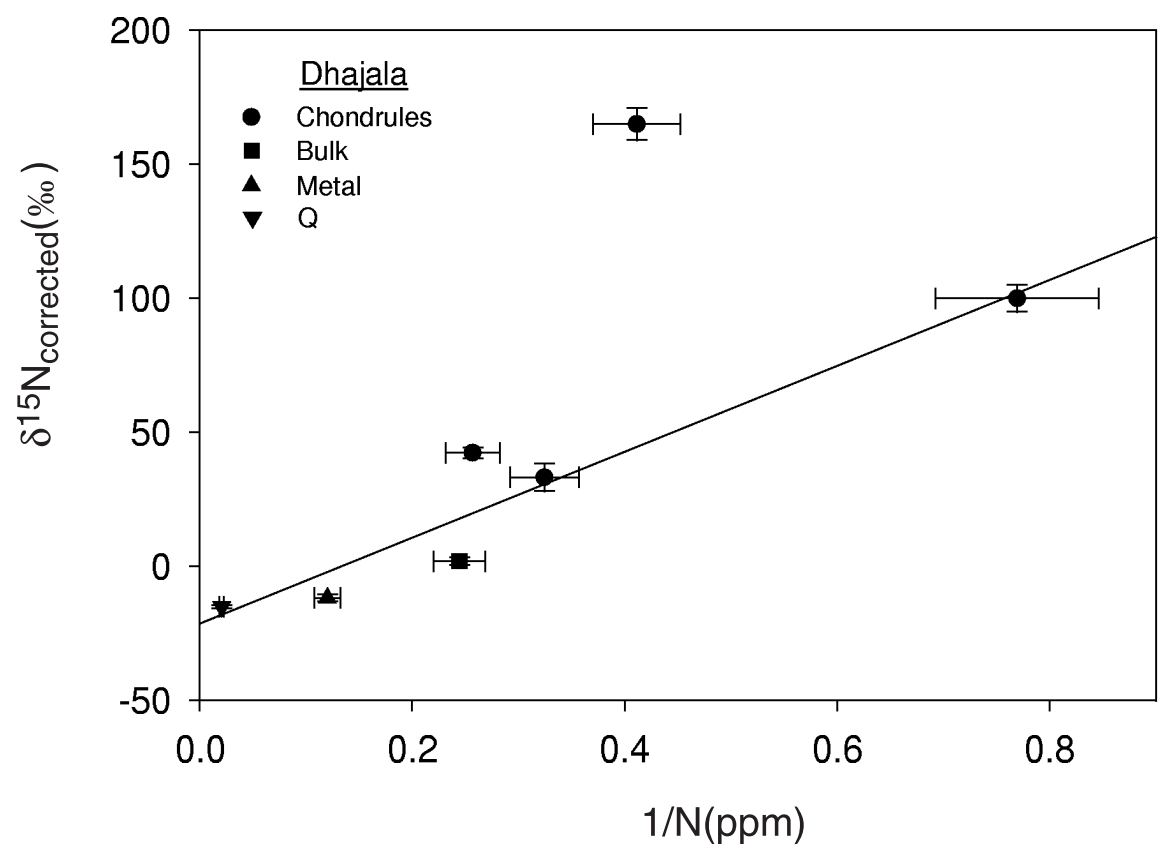

Figure 10. $\quad \delta^{15} \mathrm{~N}$ of Dhajala chondrules is plotted against 1/N. A two component mixture is indicated with variable amounts of a ${ }^{15} \mathrm{~N}$-rich component added to a component similar to $\mathrm{N}-\mathrm{Q}\left(\delta^{15} \mathrm{~N}=-15 \%\right.$ )

Dhajala chondrules. The plot of $\delta^{15} \mathrm{~N}$ vs. $1 / \mathrm{N}$ for the Dhajala chondrules along with other phases of Dhajala (figure 10) is indicative of a two component mixture (ignoring one outlier datum). This suggests an admixture of a minor ${ }^{15} \mathrm{~N}$ rich component to a major light $\mathrm{N}$ component that is similar to phase $\mathrm{Q}$ nitrogen. More data will be needed to further characterise this heavy $\mathrm{N}$ component.

\section{Conclusions}

A laser microprobe setup capable of analysing individual grains of $<1 \mathrm{mg}$ mass for noble gases and nitrogen is described. Low blanks achieved in this system allow us to analyse individual chondrules from Dhajala meteorite down to $0.172 \mathrm{mg}$ in mass. Analyses of 12 Dhajala chondrules have revealed variations in cosmogenic ${ }^{3} \mathrm{He}$ and ${ }^{21} \mathrm{Ne}$ by a factor of about 2 that are most probably due to partial gas losses, while variations by much larger factors for ${ }^{38} \mathrm{Ar}$ and ${ }^{40} \mathrm{Ar}$ are most likely a reflection of variation in chemical $(\mathrm{Ca}, \mathrm{K})$ composition among the chondrules. All the four chondrules analysed for nitrogen have shown the presence of a ${ }^{15} \mathrm{~N}$ rich component.

Apart from the analysis of microscopic phases in meteorites and terrestrial samples, a potential application for the laser microprobe would be in deciphering the noble gas isotopic records of individual presolar grains. Presolar grains isolated from meteorites have survived processing in the early solar system and have retained their unique isotopic signatures of discrete nucleosynthesis sources (Anders and Zinner 1993). The average chemical and isotopic compositions of noble gases measured in bulk separates of presolar material represent mixtures of many sources. The laser volatilization of single presolar grains can provide key insights into the stellar origins both of the grains themselves and the noble gas and nitrogen components that they carry.

\section{Acknowledgement}

The Department of Space is thanked for funds that established the laser microprobe facility. Prof. J N Goswami and Prof. G S Agarwal (Director, PRL) are thanked for their encouragement and keen interest in this project. We greatly appreciate the thorough and critical review by J N Goswami.

\section{References}

Anders E and Zinner E 1993 Interstellar grains in primitive meteorites: Diamond, siliconcarbide and graphite; Meteoritics 28 490-514

Clayton R N, Mayeda T K, Goswami J N and Olsen E J 1991 Oxygen isotope studies of ordinary chondrites; Geochim. Cosmochim. Acta 55 2317-2337

Eugster O 1988 Cosmic ray production rates for ${ }^{3} \mathrm{He},{ }^{21} \mathrm{Ne},{ }^{38} \mathrm{Ar},{ }^{83} \mathrm{Kr}$ and ${ }^{126} \mathrm{Xe}$ in chondrites based on ${ }^{81} \mathrm{Kr}-\mathrm{Kr}$ exposure ages; Geochim. Cosmochim. Acta $\mathbf{5 2}$ $1649-1662$ 
Franchi I A, Wright I P, Glbson E K Jr and Pillinger C T 1986 The laser microprobe: A technique for extracting carbon, nitrogen, and oxygen from solid samples for isotopic measurements; Proceedings of the 16th LPSC, part 2, J. Geophys. Res. 91 No. B4 D514D524

Fredriksson K 1983 Chondrules and their origins (ed. E A King) pp 44-52

Fredriksson K, Murty S V S and Marti K 1985 Some chemical and isotopic observations in chondrules; Meteoritics $20347-357$

Frick U and Pepin R O 1981 Microanalysis of nitrogen isotope abundances: association of nitrogen with noble gas carriers in Allende; Earth Planet. Sci. Lett. 56 6481

Gopalan K, Rao M N, Suthar K M and Venkatesan T R 1977 Cosmogenic and radiogenic noble gases in the Dhajala chondrite; Earth Planet. Sci. Lett. 36 341346

Göbel R, Ott U and Begemann F 1978 On trapped noble gases in ureilites; J. Geophys. Res. 83 855-67

Hohenberg C M, Nicholas R H, Olinger C $\mathrm{T}$ and Goswami J N 1990 Cosmogenic neon in individual grains of CM meteorites: Extremely long pre-compaction exposure histories or an enhanced early particle flux; Geochim. Cosmochim. Acta 54 2133-2140

Lewis R S, Srinivasan B and Anders E 1975 Host phase of a strange xenon component in Allende; Science $1901251-$ 1262

Mathew K J and Murty S V S 1993 Cosmic ray produced nitrogen in extraterrestrial matter; Proc. Indian Acad. Sci. (Earth Planet. Sci.) 102 415-437

Marti K 1969 Solar type xenon: a new isotopic composition in the Pesyanoe meteorite; Science 166 1861-74

Megrue G H 1967 Isotopic analysis of rare gases with a laser microprobe; Science 157 1555-1556

Mostefaoui S, Kita N T, Nagahara H, Togashi S and Morishita Y 1999 Aluminium-26 in two ferromagnisian chondrules from a highly unequilibrated ordinary chondrite: evidence of a short period of chondrule formation; Meteorit. Planet. Sci. 34 A84

Murty S V S 1996 Isotopic composition of nitrogen in 'Phase Q'; Earth Planet. Sci. Lett. 141 307-313
Murty S V S 1997 Noble gases and nitrogen in Muong Nong tektites; Meteorit. Planet. Sci. 32 687-691

Norris S J, Brown P W and Pillinger C T 1981 Laser pyrolysis for light element and stable isotope studies; Meteoritics $\mathbf{1 6} 369$

Okazaki R, Takaoka N, Nagao K, Sekiya M and Nakamura T 2001 Noble-gas-rich chondrules in an enstatite meteorite; Nature 412 795-498

Polnau E, Eugster O, Krahenbuhl U, and Marti K 1999 Evidence for a precompaction exposure to cosmic rays in a chondrule from the H6 chondrite ALH76008; Geochim. Cosmochim. Acta 63 925-933

Polnau E, Eugster O, Burger M, Krahenbuhl U and Marti K 2001 Precompaction exposure of chondrules and implications; Geochim. Cosmochim. Acta 65 1849-1866

Reynolds J 1960 Isotopic composition of primordial xenon. Phys. Rev. Lett. 4 351-354

Rubin E 2000 Petrologic, geochemical and experimental constraints on models of chondrule formation. Earth Sci. Rev. 50 3-27

Russel S S, Srinivasan G, Huss G R, Wasserburg G J and MacPherson G J 1996 Evidence for widespread 26Al in the solar nebula and constraints for nebular time scales; Science 273 757-762

Schelhaas N, Ott U and Begemann F 1990 Trapped noble gases in unequilibrated ordinary chondrites; Geochim. Cosmochim. Acta 54 2869-2882

Shu Frank H, Shang Hsien, Gounelle Matthieu, Glassgold Alfred E and Lee Typhoon 2001 The origin of chondrules and refractive inclusions in chondritic meteorites; The Astrophysical Journal 548 1029-1050

Wieler R, Kehm K, Meshik A P and Hohenberg C M 1996 Secular changes in the xenon and krypton abundances in the solar wind recorded in single grains; Nature $\mathbf{3 8 4} 46$ 49

Wieler R, Humbert F and Marty B 1999 Evidence for a predominantly non-solar origin of nitrogen in the lunar regolith revealed by single grain analyses; Earth Planet. Sci. Lett. 167 47-60

York Derek, Hall Charis M, Yanase Yotaro, Hanes John A and John Kenyon W $1981{ }^{40} \mathrm{Ar} /{ }^{39} \mathrm{Ar}$ dating of terrestrial minerals with a continuous laser; Geophys. Res. Lett. 8 $1136-1138$ 